Nicola Scichilone, Giuseppe Morici, Daniele Zangla, Laura Chimenti, Eva Davì, Simona Reitano, Alessandra Paternò, Roberta Santagata, Alkis Togias, Vincenzo

Bellia and Maria Rosaria Bonsignore

J Appl Physiol 109:288-294, 2010. First published Jun 10, 2010; doi:10.1152/japplphysiol.01200.2009

You might find this additional information useful...

This article cites 47 articles, 30 of which you can access free at:

http://jap.physiology.org/cgi/content/full/109/2/288\#BIBL

Updated information and services including high-resolution figures, can be found at:

http://jap.physiology.org/cgi/content/full/109/2/288

Additional material and information about Journal of Applied Physiology can be found at: http://www.the-aps.org/publications/jappl

This information is current as of October 10, 2010 . 


\title{
Effects of exercise training on airway responsiveness and airway cells in
}

\section{healthy subjects}

\author{
Nicola Scichilone, ${ }^{1}$ Giuseppe Morici, ${ }^{2,4}$ Daniele Zangla, ${ }^{3}$ Laura Chimenti, ${ }^{1,4}$ Eva Davì, ${ }^{1}$ Simona Reitano, ${ }^{1}$ \\ Alessandra Paternò, ${ }^{1}$ Roberta Santagata, ${ }^{1}$ Alkis Togias, ${ }^{5}$ Vincenzo Bellia, ${ }^{5}$ \\ and Maria Rosaria Bonsignore ${ }^{1,4}$ \\ ${ }^{1}$ Department of Internal Medicine, Division of Pulmonology (DIBIMIS), University of Palermo, "Villa Sofia-Cervello" \\ Hospital, Palermo; ${ }^{2}$ Department of Experimental Medicine, DIMES, University of Palermo, Palermo; ${ }^{3}$ Department of Motor \\ Science, DISMOT, University of Palermo, Palermo; ${ }^{4}$ Institute of Biomedicine and Molecular Immunology (IBIM), National \\ Research Council of Italy (CNR), Palermo, Italy; and ${ }^{5}$ National Institute of Allergy and Infectious Diseases, National \\ Institutes of Health, Bethesda, Maryland
}

Submitted 22 October 2009; accepted in final form 20 May 2010

Scichilone N, Morici G, Zangla D, Chimenti L, Davì E, Reitano S, Paternò A, Santagata R, Togias A, Bellia V, Bonsignore MR. Effects of exercise training on airway responsiveness and airway cells in healthy subjects. J Appl Physiol 109: 288-294, 2010. First published June 10, 2010; doi:10.1152/japplphysiol.01200.2009._Airway responsiveness to methacholine (Mch) in the absence of deep inspirations (DIs) is lower in athletes compared with sedentary individuals. In this prospective study, we tested the hypothesis that a training exercise program reduces the bronchoconstrictive effect of Mch. Ten healthy sedentary subjects (M/F: $3 / 7$; mean \pm SD age: $22 \pm 3 \mathrm{yr}$ ) entered a 10-wk indoor rowing exercise program on rowing ergometer and underwent Mch bronchoprovocation in the absence of DIs at baseline, at weeks 5 and 10 , as well as $4-6$ wk after the training program was completed. Exercise-induced changes on airway cells and markers of airway inflammation were also assessed by sputum induction and venous blood samples. Mean power output during the $1,000 \mathrm{~m}$ test was $169 \pm 49 \mathrm{~W} /$ stroke at baseline, $174 \pm 49 \mathrm{~W} /$ stroke at $5 \mathrm{wk}$, and $200 \pm 60 \mathrm{~W} / \mathrm{stroke}$ at $10 \mathrm{wk}$ of training $(P<0.05)$. The median Mch dose used at baseline was $50 \mathrm{mg} / \mathrm{ml}$ (range 25-75 $\mathrm{mg} / \mathrm{ml}$ ) and remained constant per study design. At the pretraining evaluation, the percent reduction in the primary outcome, the inspiratory vital capacity (IVC) after inhalation of Mch in the absence of DIs was $31 \pm 13 \%$; at week 5, the Mch-induced reduction in IVC was $22 \pm 19 \%, P=0.01$, and it further decreased to $15 \pm 11 \%$ at week $10(P=0.0008)$. The percent fall in IVC $4-6 \mathrm{wk}$ after the end of training was $15 \pm 11 \%(P=0.87$ vs. end of training). Changes in airway cells were not associated with changes in airway responsiveness. Our data show that a course of exercise training can attenuate airway responsiveness against Mch inhaled in the absence of DIs in healthy subjects and suggest that a sedentary lifestyle may favor development of airways hyperresponsiveness.

rowing; methacholine; neutrophils

AIRWAY SMOOTH MUSCLE tone-driven airway narrowing responses are of major importance in obstructive airway diseases. In the absence of deep inspirations, healthy subjects develop substantial bronchoconstriction with methacholine (19, 21, 42) because of the absence of the bronchoprotective and bronchodilatory effects of lung inflation. With avoidance of deep inspirations one can, therefore, study how airway tone develops and influences healthy airway function. Studying

Address for reprint requests and other correspondence: N. Scichilone, Dept. of Internal Medicine, Div. of Pulmonology (DIBIMIS), Univ. of Palermo, "Villa Sofia-Cervello" Hospital, Via Trabucco 180, 90146 Palermo, Italy (e-mail: n.scichilone@libero.it). healthy airway behavior is paramount in understanding abnormalities that are seen in asthma and other obstructive airway conditions.

Recently, we used methacholine provocations conducted in the absence of deep inspirations and discovered substantial differences among healthy individuals. Notably, we found that two groups, well-trained athletes and individuals who do not exercise vigorously in their daily life, had significantly different airway responsiveness to inhaled methacholine: in the absence of deep inspirations, the former exhibited lower responsiveness compared with the latter (35). This observation raised the hypothesis that long-term vigorous exercise reduces the bronchoconstrictive effects of parasympathetic stimulation. To test this hypothesis, we designed a prospective study in which healthy subjects entered a 10-wk indoor rowing exercise program and underwent methacholine bronchoprovocation in the absence of deep breaths at baseline, at the middle and the end of their training, as well as $4-6 \mathrm{wk}$ after the training program was completed. Rowing was chosen because it is an ideal model to assess the effects of very intense, short-lived exercise, as it involves a large muscle mass and causes intense hyperpnea (44).

Our group has also shown that endurance athletes develop neutrophilia in airway fluids $(4,5)$. The physiological consequences of this phenomenon, if any, are not known, but the possibility exists that neutrophilia may lead to inflammatory changes that, in the case of our study, may prevent or modify the hypothesized ability of exercise to reduce parasympathetically induced bronchoconstriction. To examine the influence of exercise-induced changes on airway cells, we included sputum induction procedures in our study. Markers of airway inflammation were assessed by Clara cell protein 16 in serum (CC16) and interleukin-8 (IL-8) in sputum supernatants.

\section{MATERIALS AND METHODS}

Subjects. We studied 10 healthy subjects (M/F: 3/7; mean \pm SD age: $22 \pm 3 \mathrm{yr}$, body mass index: $22.2 \pm 2.3 \mathrm{~kg} / \mathrm{m}^{2}$ ). No subject was a former or current smoker or reported symptoms suggestive of airway disease nor did any subject have a prior history of chronic airway disease. Two subjects had a history of allergic rhinitis but were untreated and asymptomatic at the time of the study. No subject reported upper respiratory infections in the $4 \mathrm{wk}$ preceding enrollment. Physical activity before enrollment was moderate $(<4 \mathrm{~h} / \mathrm{wk}$ in the previous $6 \mathrm{mo}$ ), and no subject practiced regular training of any form. In the days when tests were performed, exercise, as well as 
coffee or tea, was not allowed in the morning. The study was approved by the University of Palermo Ethics Committee, and all subjects gave written informed consent.

Training program. All subjects underwent a training indoor rowing program on rowing ergometer (Concept II, Morrisville, VT) consisting of two to three sessions per week for $10 \mathrm{wk}$ (total 25 sessions). Each session lasting 60-90 min included a warm-up period for $20 \mathrm{~min}$ (running and stretching) and a specific training on rowing ergometer of 40-70 min. A 1,000-m all-out rowing test was first performed to document power output, strokes, and mean maximal speed $(29,30)$.

The 1,000-m all-out test was preceded by a 20-min warm-up: after $10 \mathrm{~min}$ of low-intensity exercise (heart rate 120-140 beats/min, 22-26 strokes/min), the subject performed two to three sprints of five to seven strokes at submaximal intensity (heart rate $140-160$ beats/min, 27-30 strokes/min). Active rest (2 min of light rowing, 22-24 strokes/ min) was maintained between sprints. The warm-up ended with two to three trials at maximal intensity preceded and followed by short active rest periods. On the basis of the performance, watts per stroke and strokes per minute recorded in the 1,000-m all-out test, a certified European rowing coach created personalized training programs. Rowers undertook a 10 -wk training program of $20 \%$ of all training time at maximal power output, $10 \%$ of all training time at $75-90 \%$ of maximal power output, and $70 \%$ of all training time at $60-65 \%$ of maximal power output. At weeks 0, 5, and 10,1,000- and 2,000-m all-out rowing tests were performed to evaluate performance and reassess the individualized workload. A certified training instructor and a pulmonologist supervised all sessions.

Pretraining clinical evaluation. At the beginning of the study and before the training program began, in addition to providing a clinical history, each subject underwent a functional evaluation to exclude the presence of respiratory disease. Functional respiratory assessment included conventional spirometry and measures of static and dynamic lung volumes, using the helium dilution technique and a computerized water-sealed spirometer (Biomedin; Padua, Italy). Measurements were made in accordance with the American Thoracic Society (ATS) acceptability and reproducibility criteria (1).

Study design. At the pretraining evaluation (week 0), modified spirometry (see below) was first conducted followed by determination of airway responsiveness to methacholine in the absence of deep inspirations; in addition, induced sputum and venous blood samples were collected at rest on the following day. The same protocol was repeated at weeks 5 (midtraining) and 10 (end of training), as well as 4-6 wk after the end of the training program (recovery). During the recovery period subjects were asked not to engage in any training activity.

Assessment of airway responsiveness in the absence of deep inspirations. To evaluate airway responsiveness in the absence of deep inspirations, we employed the single-dose methacholine bronchoprovocation procedure that we have previously used and validated in several studies $(35,36,38)$. The protocol for the single-dose methacholine provocation is depicted in Fig. 1. At baseline, three acceptable, modified (see below) spirometric maneuvers are obtained. Subjects are then instructed to avoid deep inspirations for $20 \mathrm{~min}$ and are observed for compliance during this period. Thereafter, subjects inhale a single methacholine dose with five tidal breaths, and $3 \mathrm{~min}$ later, a single modified spirometry is repeated.

Because the deep inspiratory maneuver that is embedded in conventional spirometry can alter the response to methacholine $(11,39)$, a modified spirometry technique is used in our studies (Fig. 1, inset). The modified spirometry incorporates a partial forced expiratory maneuver (from end tidal inspiration to residual volume) immediately before the maximal maneuver. Inspiratory vital capacity (IVC), i.e., the volume from the end of the forced partial expiratory maneuver to the end of maximal inspiration, is recorded and is used as the primary outcome of the methacholine provocation, because it offers the advantage of not being affected by a preceding deep inspiration. The usage of IVC does not eliminate our ability to also measure forced expira-

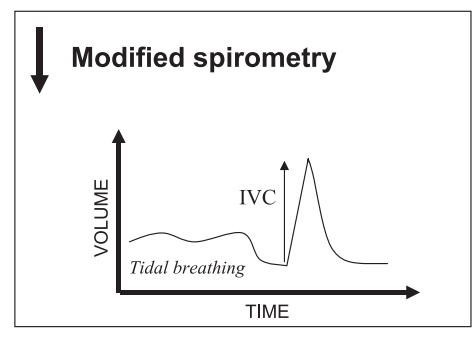

Single Dose

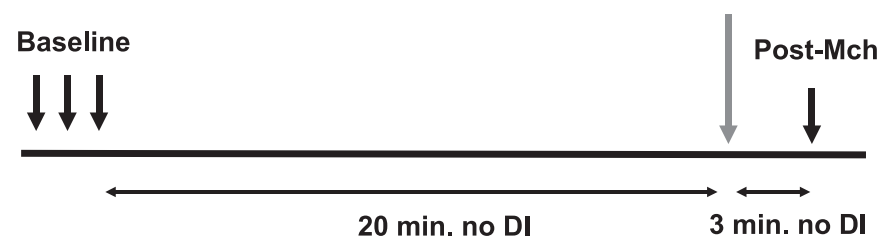

Fig. 1. Single-dose methacholine (Mch) bronchoprovocation protocol. Inset: modified spirometric maneuver that was used in the study. This consists of a partial forced expiratory immediately followed by a maximal inspiratory maneuver. Inspiratory vital capacity (IVC) is the volume from the end of the forced partial expiratory maneuver to the end of maximal inspiration and represents the primary outcome of the methacholine provocation. DI, deep inspiration.

tory volume in $1 \mathrm{~s}\left(\mathrm{FEV}_{1}\right)$ and forced vital capacity (FVC) since a maximal maneuver always follows the partial one. The methacholineinduced effect on IVC is recorded as the percent difference between the post-methacholine IVC and the best IVC from the three baseline, modified spirometric measurements.

The dose of methacholine used in the pretraining bronchoprovocation was individualized as the inhaled concentration attaining at least $15 \%$ reduction in IVC from baseline and was determined for each subject by a series of increasing single-dose methacholine bronchoprovocations carried out earlier, also in the absence of deep breaths. If the first concentration $(7.5 \mathrm{mg} / \mathrm{ml})$ was ineffective, the provocation was repeated with a higher concentration $(25 \mathrm{mg} / \mathrm{ml})$ and, if needed, with the highest concentration $(75 \mathrm{mg} / \mathrm{ml})$. These single-dose methacholine bronchoprovocations were repeated on the same day (at least $2 \mathrm{~h}$ apart) if the preceding provocation reduced IVC by $<5 \%$ from baseline or on the following day if IVC had dropped by $>5 \%$. The concentration of methacholine that was used for the single-dose challenge in the pretraining bronchoprovocation was used in all subsequent bronchoprovocations.

Sputum induction and processing. Sputum was induced and processed in accordance with the "plugs" method (23) with slight modifications (33). After washing the oral cavity with saline, subjects inhaled a hypertonic (5\%) saline aerosol for 20 min administered with an ultrasonic nebulizer (median particle diameter $2.5 \mu \mathrm{m}$, output 1 $\mathrm{ml} / \mathrm{min}$; Fisoneb, Fisons Italchimici Spa, Rome, Italy). They were then asked to cough and expectorate sputum into 50-ml sterile containers. Samples were spread in a Petri dish, and mucus plugs were selected and weighted. PBS was added to the plugs in a $4: 1$ weight ratio. Samples were then gently mixed and centrifuged (800 $g$ for 20 min) and supernatants were aspirated and frozen at $-20^{\circ} \mathrm{C}$ for analysis of IL-8.

The cell pellets from the mucus plugs were resuspended in $0.1 \%$ dithiothreitol-saline solution (DTT, Sigma, St. Louis, MO) at a 4:1 weight ratio and gently mixed and agitated at $25^{\circ} \mathrm{C}$ for $20 \mathrm{~min}$. The samples were then filtered (nylon filter, $70 \mu \mathrm{m}$ ), and centrifuged (800 $g$ for $10 \mathrm{~min}$ ). Cell pellets were again resuspended in $2 \%$ human serum albumin-saline solution. Total cell count and viability were determined with a standard hemocytometer and Trypan blue exclusion. Cells were then cytocentrifuged (Cytospin 2, Shandon Instruments, Runcorn, UK) and stained with Diff-Quick (Merz-Dade, Dudingen, Switzerland). The slides were read by two investigators 
who counted at least 400 cells/slide. Slide readers were unaware of the sample's origin (subject ID or time point).

Biochemical analysis on plasma, serum, and sputum supernatants. Clara cell protein $16(\mathrm{CC}-16)$ is a $16-\mathrm{kDa}$ protein released from nonciliated pulmonary epithelia cells (Clara cells) in the lungs (18). The rationale for using CC-16 lies in the fact that it has been used as a marker of increased lung epithelial permeability (18), which may occur after intense exercise. Indeed, CC-16 has been found to be increased during (8), or shortly after, exercise (31). Because of its small size, CC-16 diffuses across the bronchoalveolar/capillary barrier and can be detected in serum (18). We reasoned that changes in markers of lung damage would impact on the beneficial effect of exercise. CC-16 was measured in serum with an ELISA sensitive to 2 $\mathrm{ng} / \mathrm{ml}$ (BioVendor). Sputum supernatants were analyzed for IL-8, known to mediate recruitment of neutrophils $(2,22)$, with an ELISA sensitive to $26 \mathrm{pg} / \mathrm{ml}$ ( $\mathrm{R} \& \mathrm{D}$ Systems).

Statistical analysis. Data are reported as means \pm SD. Different time points and experimental conditions were compared by ANOVA; the Bonferroni test was used for post hoc comparisons. Nonparametric tests were used for nonnormally distributed variables. The statistical package we employed was StatView 5.0.1 (Abacus Concept, Berkeley, CA). Statistical significance was accepted at $P<0.05$.

\section{RESULTS}

The functional characteristics of the study sample are summarized in Table 1. On average, subjects attended $18 \pm 3$ training sessions $(71 \pm 15 \%$ of the sessions required by protocol). Performance was evaluated during training by 1,000- and 2,000-m all-out rowing tests at 5 and $10 \mathrm{wk}$. Mean power output during the 1,000-m test was $169 \pm 49 \mathrm{~W} /$ stroke at week 0, $174 \pm 49 \mathrm{~W} /$ stroke at $5 \mathrm{wk}$, and $200 \pm 60 \mathrm{~W} /$ stroke at $10 \mathrm{wk}$ of training $(P<0.05)$; similarly, mean power output in the 2,000-m test increased from $148 \pm 37$ to $175 \pm 61$ $\mathrm{W} /$ stroke from weeks 1 to $10(P<0.05)$. This improvement in performance was as expected and confirmed the effectiveness of the training program.

Spirometry and airway responsiveness. Lung volumes and spirometric outcomes at rest were unaffected by training (Table 1). The median methacholine dose used in the group of subjects at baseline was $50 \mathrm{mg} / \mathrm{ml}$ (range $25-75 \mathrm{mg} / \mathrm{ml}$ ) and remained constant per study design. At the pretraining evaluation, the percent reduction in IVC after inhalation of methacholine in the absence of deep inspirations was $31 \pm 13 \%$, in agreement with previous data obtained in healthy subjects (35). The reduction in $\mathrm{FEV}_{1}$ during the same evaluation was $38 \pm$ $14 \%$, and the reduction in the $\mathrm{FEV}_{1} / \mathrm{FVC}$ ratio was $21 \pm 8.8 \%$. At week 5 (midtraining), the methacholine-induced reduction in IVC was $22 \pm 19 \%(P=0.01$ compared with the pretraining provocation). At the end of training (week 10), the magnitude of the methacholine-induced reduction in IVC further

Table 1. Functional characteristics of the study sample before and at the end of training

\begin{tabular}{lccc}
\hline \hline & Pretraining & Posttraining & $P$ Value \\
\hline FEV $_{1}, \%$ predicted & $111 \pm 12$ & $110 \pm 12$ & 0.64 \\
FVC, \% predicted & $110 \pm 12$ & $106 \pm 13$ & 0.08 \\
TLC, \% predicted & $106 \pm 12$ & $110 \pm 11$ & 0.09 \\
FRC, \% predicted & $109 \pm 31$ & $101 \pm 31$ & 0.08 \\
RV, \% predicted & $104 \pm 19$ & $99 \pm 23$ & 0.25 \\
\hline
\end{tabular}

Data are expressed as means $\pm \mathrm{SD}$. $\mathrm{FEV}_{1}$, forced expiratory volume in $1 \mathrm{~s}$; FVC, forced vital capacity; TLC, total lung capacity; FRC, functional residual capacity; RV, residual volume.

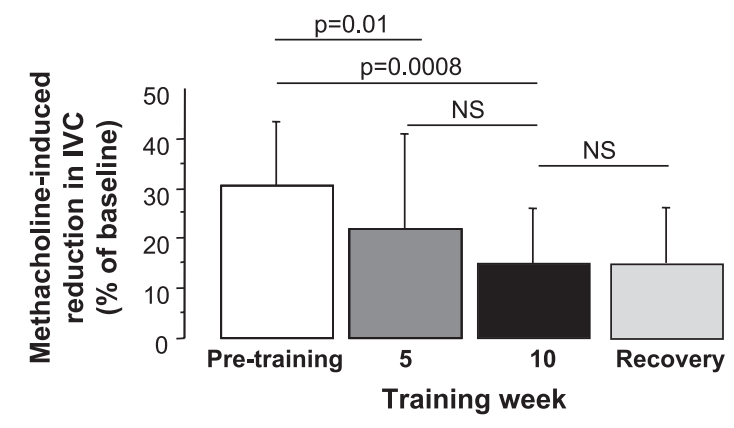

Fig. 2. Single-dose methacholine-induced reductions in IVC from baseline in the absence of deep inspirations, at baseline, after 5 and $10 \mathrm{wk}$ of rowing exercise, and 4-6 wk after the exercise program had ended (recovery). Bars represent means $\pm \mathrm{SD}$. NS, not significant.

decreased to $15 \pm 11 \%(P=0.0008$ compared with the pretraining provocation), although the difference between weeks 5 and 10 did not reach significance $(P=0.10)$ (Fig. 2). Individual data points for percent reduction in IVC during training are also presented in Fig. 3. A similar trend was found for $\mathrm{FEV}_{1}$ : the percent fall in $\mathrm{FEV}_{1}$ in the absence of deep breaths was $38 \pm 14 \%$ at the pretraining provocation, $26 \pm$ $21 \%$ at midtraining, and $20 \pm 11 \%$ at end of training (repeatedmeasures ANOVA: $P=0.008$ ). The methacholine-induced reduction in $\mathrm{FEV}_{1}$ and in $\mathrm{FEV}_{1} / \mathrm{FVC}$ at the end of training were significantly lower than that at baseline $(P=0.004$ and $P=0.04$, respectively).

Pretraining to posttraining changes in airway responsiveness, as assessed by the reduction in IVC in the absence of deep inspirations, were not associated with changes in lung volumes [for total lung capacity (TLC): $r=0.20, P=0.59$; for functional residual capacity (FRC): $r=0.21, P=0.55]$, a finding that argues against the possibility of the reduction in airway responsiveness being secondary to modifications in individual lung volumes. Also, the change in the percent reduction in IVC between the beginning and the end of training did not relate to the level of adherence to the training program ( $r=0.02, P=0.96$ ) nor with the airway response to methacholine at baseline $(r=0.53, P=0.11)$.

To test whether any changes that occurred during the training period were persistent, further evaluation was conducted 4-6 wk after the end of training (recovery). The dose of methacholine used in this bronchoprovocation was the same as that used in all previous evaluations. The results did not differ from those obtained during the end of training provocation: the percent fall in IVC at recovery was $15 \pm 11 \%(P=0.87$ vs.

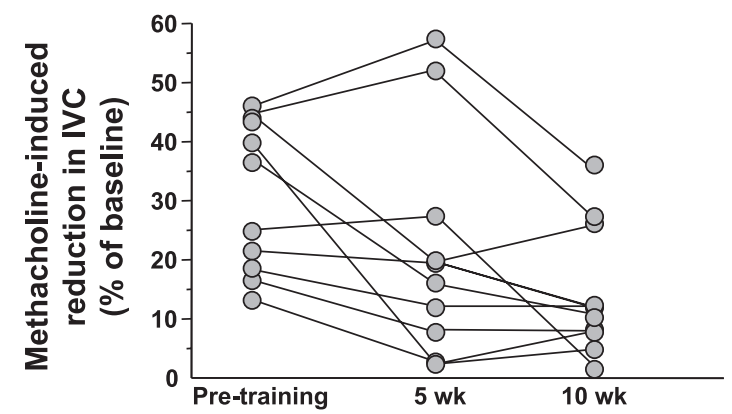

Fig. 3. Individual data for methacholine-induced percent reduction in IVC from baseline obtained at baseline and after $10 \mathrm{wk}$ of rowing exercise training. 
end of training) (Fig. 2); similarly, the percent fall in $\mathrm{FEV}_{1}$ at recovery was $20 \pm 11 \%$ ( $P=0.95$ vs. end of training).

Airway cells. Adequate sputum samples were obtained in eight subjects; two subjects were consistently unable to expectorate. Absolute and differential cell counts are reported in Fig. 4. The total number of cells collected in induced sputum was unaffected by training. The absolute neutrophil counts did not change from baseline to midtraining (week 5) but significantly increased from midtraining to end of training (week 10 vs. week $5, P<0.004)$ and were back to baseline at recovery. No difference was recorded between recovery and week $10(P=$ $0.13)$. The absolute neutrophil count at the end of training was not different from baseline $(P=0.57)$. Bronchial epithelial cells at 5 and $10 \mathrm{wk}$ of training, as well as at recovery, were reduced from baseline with the latter two differences reaching statistical significance $(P<0.01)$.

We conducted simple regression analyses in the attempt to assess whether increased numbers of sputum neutrophils or changes in other airway cells were inversely associated with the reduction in airway responsiveness with training. These analyses did not show any relationship between the trainingassociated changes in airway responsiveness and changes in absolute neutrophil cell counts $(r=0.25, P=0.49)$, macrophage $(r=0.02, P=0.98)$, or bronchial cell counts $(r=0.12$, $P=0.78)$.

Inflammatory mediators in induced sputum and blood. In the induced sputum supernatants, the concentration of IL-8 was significantly higher at end of training $(P<0.03)$ and returned back to baseline at recovery $(468 \pm 273 \mathrm{pg} / \mathrm{ml}$ at baseline, $356 \pm 182$ at midtraining, and $966 \pm 600$ at the end of training, Fig. 5). Serum CC-16 concentration did not change during training (pretraining: $4.4 \pm 1.4 \mathrm{ng} / \mathrm{ml}$; week $5: 4.1 \pm 0.9 \mathrm{ng} / \mathrm{ml}$; week 10: $5.2 \pm 1.7 \mathrm{ng} / \mathrm{ml}$; recovery: $5.3 \pm 0.8 \mathrm{ng} / \mathrm{ml}, P=$ 0.86) (Fig. 5). No relationship was found between the traininginduced changes from baseline in airway responsiveness at the end of training and those in sputum IL-8 or serum CC-16 ( $r=$ $0.32, P=0.56$ and $r=0.06, P=0.90$, respectively).
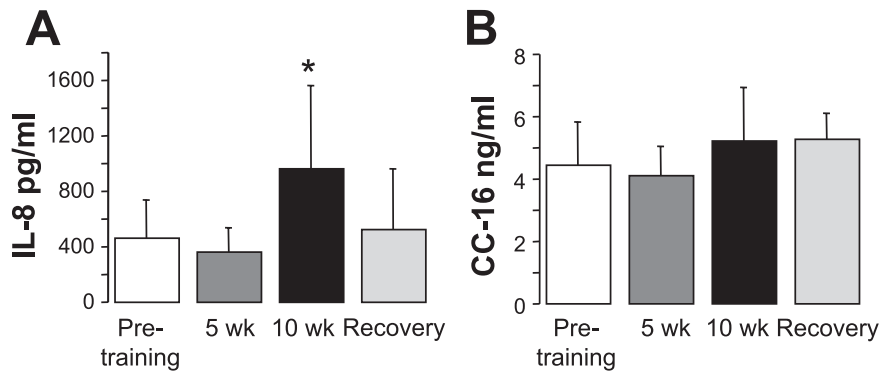

Fig. 5. Absolute values for IL-8 and CC-16 during training and after recovery. Bars represent means $\pm \mathrm{SD}$. $* P<0.03$, week 10 vs. baseline.

\section{DISCUSSION}

This study was designed to test the hypothesis that long-term training reduces the bronchoconstrictive effects of inhaled methacholine. Our results clearly show that airway responsiveness to methacholine decreases with training in healthy subjects; this effect, an $\sim 50 \%$ inhibition of the methacholineinduced drop in lung function, became apparent after $5 \mathrm{wk}$ of training and persisted for at least $1 \mathrm{mo}$ after training cessation. Our results are in line with those reported in other studies, albeit with different designs. For example, Freedman and colleagues (15) showed that exercise and voluntary hyperventilation similarly decreased airway resistance induced by methacholine inhalation in healthy subjects. Also, our group previously reported a state of hyporesponsiveness to methacholine in the absence of deep inspirations in healthy amateur runners compared with sedentary, age-matched control subjects (35). The attenuation of the methacholine-induced reduction in both IVC and $\mathrm{FEV}_{1}$ following the training program, as well as in the $\mathrm{FEV}_{1} / \mathrm{FVC}$, suggests that exercise exerts its beneficial effect by preventing (or attenuating) airway closure and large airway narrowing (9).

The second goal of this study was to examine what influence, if any, do training-induced inflammatory changes in the
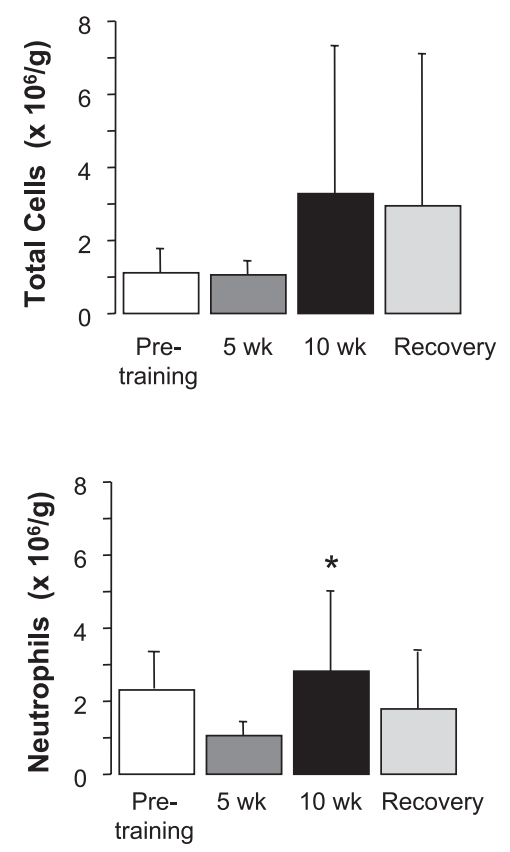
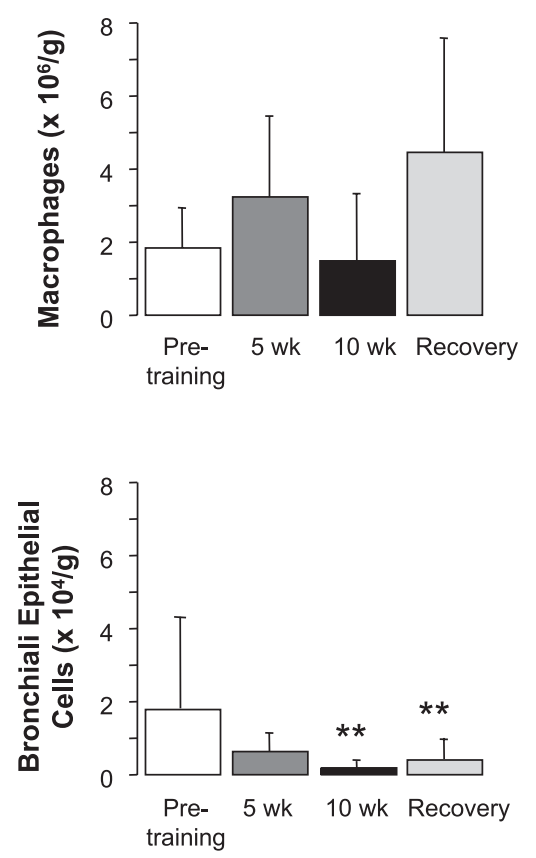

Fig. 4. Absolute cell counts in induced sputum at baseline, after 5 and $10 \mathrm{wk}$ of rowing exercise training, and $4-6 \mathrm{wk}$ after the end of the exercise program (recovery). $* P<$ 0.004 , week 10 vs. week 5 . $* * P<0.01$, weeks 5 and 10 vs. baseline. 
airways have on the beneficial effects of training on airway responsiveness. Several studies indicate that endurance exercise increases inflammatory cells in the airways. Increased airway neutrophil counts were described in endurance athletes of winter $(20,45)$ or summer sports $(4,6,29)$, both at rest and after exercise. In trained mice, we previously reported increased inflammatory cells and damaged bronchial epithelium in small airways (10). Our results agree with those of Denguezli and coworkers (13), who reported a progressive increase in IL-8 in induced sputum during training. However, a long training history may be necessary before significant changes in airway inflammatory markers fully develop in young athletes (32), in line with the possibility that intensive prolonged training may eventually result in airway damage. Overall, the mild changes in airway cells observed during exercise training showed a different time course compared with changes in airway responsiveness. Our analyses do not support the hypothesis that these changes have any impact on the effect of training on airway responsiveness.

Our study was conducted in healthy subjects. Although there are no known benefits of reducing airway responsiveness in people who do not have airway disease, increased airway responsiveness has been epidemiologically associated with sedentary lifestyle (40) and with obesity (41), conditions that predispose to various health problems. In the future, it may be of value to investigate the significance of the population variance in airway responsiveness, in the absence of overt airway disease. Since asymptomatic airway hyperresponsiveness has been associated with later development of asthmatic symptoms (27) or with accelerated decline in lung function (26), we can speculate that any factor reducing the degree of airway responsiveness theoretically would delay the occurrence of asthmatic symptoms or slow the lung function decline. From the methodological standpoint, it was important to first test our hypothesis in nonasthmatics. This allowed us to determine whether the anticipated effect of exercise alters the baseline, physiological responsiveness of the airways to methacholine. A similar study in mild asthma, to examine whether hyperresponsiveness to methacholine can be altered by exercise and whether this effect can have beneficial clinical consequences, should be conducted. In support of the possibility that exercise may benefit patients with asthma, we have recently documented decreased airway responsiveness to methacholine in children with mild asthma after 12-wk endurance training (7). However, the medical literature is inconsistent as to the beneficial effect of exercise in preventing induced bronchoconstriction and improving respiratory symptoms. In a study involving eight individuals with asthma (12), the authors showed impressive immediate reversal of airway narrowing during exercise, likely due to the mechanical stretching of the tidal breaths on the airway walls, although a direct effect of catecholamines on airway smooth muscle cannot be excluded. Intriguing findings on the effect of physical activity on airway hyperresponsiveness have been reported by a multicenter, cross-sectional European survey on 5,158 subjects (40). In this study, both frequency and duration of physical activity were inversely related to airway hyperresponsiveness. In addition, regular physical activity was associated with reduced risk of exacerbations in women with asthma in a longitudinal study (16). On the other hand, significantly higher prevalence of airway hyperresponsiveness in elite athletes has been documented (25).

Several mechanisms can be advocated to explain the beneficial effects of physical exercise on airway responsiveness. Spirometric outcomes and lung volumes did not change after training, nor was there any correlation between individual changes in lung volumes and changes in methacholine responsiveness. This reasonably argues against the possibility that the observed changes in airway responsiveness are causally linked to changes in lung volumes. We favor the hypothesis that the intensive lung excursions associated with exercise result in airway smooth muscle stretch and may induce functional changes leading to reduction in smooth muscle contractility. In vitro studies have investigated the response of smooth muscle cells to stretch in great detail. Fredberg and colleagues (14) have demonstrated that the force generation of tracheal smooth muscle strips decreased with increasing amplitude and duration of the applied strain. The physiological range of tidal muscle stretch is $\sim 4 \%$ of muscle length during spontaneous breathing and rises up to $12 \%$ during sigh and even more during exercise (14). Stretching airway smooth muscle by $3 \%$ of muscle length reduces force generation by $50 \%$ (17), possibly because of plastic reorganization and dynamic changes of the contractile apparatus. Functional studies indicate that adaptation of airway smooth muscle to different length change is a two-step process: first (within minutes) there is a decrease in the ability of muscle to generate force; this is followed by the structural reorganization of the contractile apparatus, that would lead to a full adaptation of the muscle to the new state $(24,34,47)$. On the basis of this extensive work on airway smooth muscle function, we speculate that deep inspirations associated with regular physical exercise, such as in our protocol, could stretch airway smooth muscle and reduce its contractility, which remains attenuated during the state of deep inspiration avoidance. This is indirectly suggested by a study conducted in sheep that were chronically subjected to breathing at low lung volumes using a corset for $4 \mathrm{wk}$ (28). The rate of stress generation of the airway smooth muscle significantly increased, with no change in the content or activity of myosin light-chain kinase. The authors proposed that the increased contractility was due to reorganization of the contractile apparatus of the smooth muscle. One should add that regular endurance training could potentiate the effectiveness of the skeletal muscle of the rib cage and the diaphragm, which would, in turn, amplify lung excursions and stretching of the airways. It is possible that exercise results in the release of bronchoprotective mediators, such as catecholamines and nitric oxide. In this regard, the lack of association between the level of adherence to exercise and the outcome of the study is in favor of the occurrence of humoral mechanisms. However, there is no evidence that these mediators have long-term effects as those observed in our study. Also, hyperpnea can cause bronchodilation even with normal levels of plasma catecholamines (3) and inhibition of NO synthase does not alter lung function in asthmatics during exercise (46). Finally, although the possibility of alveolar growth after intense exercise cannot be excluded (1a), we find unlikely that rowing had an effect on alveolar hyperplasia/ hypertrophy in our study because the training program was shorter and less intensive than that reported in literature.

Whether the observed effect of training on airway responsiveness is specifically associated with the rowing exercise is 
an interesting topic for further work. At this stage, we do not have information on the specificity of this phenomenon with regard to the type of exercise, nor do we know whether increased rates of diaphragmatic excursions in the absence of exercise, such as in incentive spirometry, would have a similar effect.

In conclusion, we have found that a 10 -wk course of exercise training results in $\sim 50 \%$ attenuation of the airway responsiveness against methacholine, inhaled in the absence of deep inspirations, in healthy subjects. Small changes in airway cells were detected, but with no association to the changes in airway responsiveness. Our data support the need for expanding this line of research in asthma. In addition, our observations imply that a sedentary lifestyle may favor development of airways hyperresponsiveness, in agreement with recent epidemiological data.

\section{DISCLOSURES}

No conflicts of interest, financial or otherwise, are declared by the author(s).

\section{REFERENCES}

1. American Thoracic Society. Standardization of Spirometry, 1994 Update. American Thoracic Society. Am J Respir Crit Care Med 152: 1107-1136, 1995.

1a.Armour J, Donnelly PM, Bye PT. The large lungs of elite swimmers: an increased alveolar number? Eur Respir J 6: 237-47, 1993.

2. Baggiolini M, Deranleau DA, Dewald B, Thelen M, von Tscharner V, Wymann MP. [Properties and activation mechanism of neutrophilic leukocytes]. Arzneimittelforschung 39: 177-180, 1989.

3. Barnes PJ, Brown MJ, Silverman M, Dollery CT. Circulating catecholamines in exercise and hyperventilation induced asthma. Thorax 36: 435-440, 1981.

4. Bonsignore MR, Morici G, Riccobono L, Insalaco G, Bonanno A, Profita M, Paterno A, Vassalle C, Mirabella A, Vignola AM. Airway inflammation in nonasthmatic amateur runners. Am J Physiol Lung Cell Mol Physiol 281: L668-L676, 2001.

5. Bonsignore MR, Morici G, Vignola AM, Riccobono L, Bonanno A, Profita M, Abate P, Scichilone N, Amato G, Bellia V, Bonsignore G. Increased airway inflammatory cells in endurance athletes: what do they mean? Clin Exp Allergy 33: 14-21, 2003.

6. Bonsignore MR, Morici G, Riccobono L, Profita M, Bonanno A, Paternò A, Di Giorgi R, Chimenti L, Abate P, Mirabella F, Maurizio Vignola A, Bonsignore G. Airway cells after swimming outdoors or in the sea in nonasthmatic athletes. Med Sci Sports Exerc 35: 1146-1152, 2003.

7. Bonsignore MR, La Grutta S, Cibella F, Scichilone N, Cuttitta G, Interrante A, Marchese M, Veca M, Virzi' M, Bonanno A, Profita M, Morici G. Effects of exercise training and montelukast in children with mild asthma. Med Sci Sports Exerc 40: 405-412, 2008.

8. Broeckaert F, Arsalane K, Hermans C, Bergamaschi E, Brustolin A, Mutti A. Serum Clara cell protein: a sensitive biomarker of increased lung epithelium permeability caused by ambient ozone. Environ Health Perspect 108: 533-537, 2000.

9. Brown RH, Pearse DB, Pyrgos G, Liu MC, Togias A, Permutt S. The structural basis of airways hyperresponsiveness in asthma. $J$ Appl Physiol 101: 30-39, 2006.

10. Chimenti L, Morici G, Paternò A, Bonanno A, Siena L, Licciardi A, Veca M, Guccione W, Macaluso F, Bonsignore G, Bonsignore MR. Endurance training damages small airway epithelium in mice. Am J Respir Crit Care Med 175: 442-449, 2007.

11. Crimi E, Pellegrino R, Milanese M, Brusasco V. Deep breaths, methacholine, and airway narrowing in healthy and mild asthmatic subjects. $J$ Appl Physiol 93: 1384-1390, 2002.

12. Crimi E, Pellegrino R, Smeraldi A, Brusasco V. Exercise-induced bronchodilation in natural and induced asthma: effects on ventilatory response and performance. J Appl Physiol 92: 2353-23560, 2002.

13. Denguezli M, Ben Chiekh I, Ben Saad H, Zaouali-Ajina M, Tabka Z, Abdelkrim Z. One-year endurance training: effects on lung function and airway inflammation. J Sports Sci 26: 1351-1359, 2008.
14. Fredberg JJ, Inouye D, Miller B, Nathan M, Jafari S, Raboudi SH, Butler JP, Shore SA. Airway smooth muscle, tidal stretches, and dynamically determined contractile states. Am J Respir Crit Care Med 156: 1752-1759, 1997.

15. Freedman S, Lane R, Gillett MK, Guz A. Abolition of methacholine induced bronchoconstriction by the hyperventilation of exercise or volition. Thorax 43: 631-636, 1988.

16. Garcia-Aymerich J, Varraso R, Anto JM, Camargo CA Jr. Prospective study of physical activity and risk of asthma exacerbations in older women. Am J Respir Crit Care Med 179: 999-1003, 2009.

17. Gump A, Haughney L, Fredberg J. Relaxation of activated airway smooth muscle: relative potency of isoproterenol vs. tidal stretch. J Appl Physiol 90: 2306-2310, 2001.

18. Hermans C, Bernard A. Lung epithelium-specific proteins: characteristics and potential applications as markers. Am J Respir Crit Care Med 159: 646-678, 1999.

19. Kapsali T, Permutt S, Laube B, Scichilone N, Togias A. Potent bronchoprotective effect of deep inspiration and its absence in asthma. $J$ Appl Physiol 89: 711-720, 2000.

20. Karjalainen EM, Laitinen A, Sue-Chu M, Altraja A, Bjermer L, Laitinen LA. Evidence of airway inflammation and remodeling in ski athletes with and without bronchial hyperresponsiveness to methacholine. Am J Respir Crit Care Med 161: 2086-2091, 2000.

21. King GG, Moore BJ, Seow CY, Pare PD. Time course of increased airway narrowing caused by inhibition of deep inspiration during methacholine challenge. Am J Respir Crit Care Med 160: 454-457, 1999.

22. Kobayashi Y. The role of chemokines in neutrophil biology. Front Biosci 13: 2400-2407, 2008

23. Koller DY, Nething I, Otto J, Urbanek R, Eichler I. Cytokine concentrations in sputum from patients with cystic fibrosis and their relation to eosinophil activity. Am J Respir Crit Care Med 155: 1050-1054, 1997.

24. Kuo KH, Wang L, Pare PD, Ford LE, Seow CY. Myosin thick filament lability induced by mechanical strain in airway smooth muscle. $J$ Appl Physiol 90: 1811-1816, 2001.

25. Langdeau JB, Turcotte H, Bowie DM, Jobin J, Desgagne P, Boulet LP. Airway hyperresponsiveness in elite athletes. Am J Respir Crit Care Med 161: 1479-1484, 2000.

26. Lange P, Parner J, Vestbo J, Schnohr P, Jensen G. A 15-year follow-up study of ventilatory function in adults with asthma. N Engl J Med 339: 1194-1200, 1998.

27. Laprise C, Boulet LP. Asymptomatic airway hyperresponsivness: a three-year follow-up. Am J Respir Crit Care Med 156: 403-409, 1997.

28. McClean MA, Matheson MJ, McKay K, Johnson PR, Rynell AC, Ammit AJ, Black JL, Berend N. Low lung volume alters contractile properties of airway smooth muscle in sheep. Eur Respir $J$ 22: 50-56, 2003

29. Morici G, Bonsignore MR, Zangla D, Riccobono L, Profita M, Bonanno A, Paternò A, Di Giorgi R, Mirabella F, Chimenti L, Benigno A, Vignola AM, Bellia V, Amato G, Bonsignore G. Airway cell composition at rest and after an all-out test in competitive rowers. Med Sci Sports Exerc 36: 1723-1729, 2004.

30. Morici G, Zangla D, Santoro A, Pelosi E, Petrucci E, Gioia M, Bonanno A, Profita M, Bellia V, Testa U, Bonsignore MR. Supramaximal exercise mobilizes hematopoietic progenitors and reticulocytes in athletes. Am J Physiol Regul Integr Comp Physiol 289: R1496-R1503, 2005.

31. Nanson CJ, Burgess JL, Robin M, Bernard A. Exercise alters serum pneumoprotein concentrations. Resp Physiol 127: 259-265, 2001.

32. Pedersen L, Lund TK, Barnes PJ, Kharitonov SA, Backer V. Airway responsiveness and inflammation in adolescent elite swimmers. J Allergy Clin Immunol 122: 322-327, 2008.

33. Popov TA, Pizzichini MM, Pizzichini E, Kolendowicz R, Punthakee Z, Dolovich J, Hargreave FE. Some technical factors influencing the induction of sputum for cell analysis. Eur Respir J 8: 559-565, 1995.

34. Pratusevich VR, Seow CY, Ford LE. Plasticity in canine airway smooth muscle. J Gen Physiol 105: 73-94, 1995.

35. Scichilone N, Morici G, Marchese R, Bonanno A, Profita M, Togias A, Bonsignore MR. Reduced airway responsiveness in nonelite runners. Med Sci Sports Exerc 37: 2019-2025, 2005.

36. Scichilone N, Kapsali T, Permutt S, Togias A. Deep inspiration-induced bronchoprotection is stronger than bronchodilation. Am J Respir Crit Care Med 162: 910-916, 2000. 
37. Scichilone N, Permutt S, Bellia V, Togias A. Inhaled corticosteroids and the beneficial effect of deep inspiration in asthma. Am J Respir Crit Care Med 172: 693-699, 2005.

38. Scichilone N, Permutt S, Togias A. The lack of the bronchoprotective and not the bronchodilatory ability of deep inspiration is associated with airway hyperresponsiveness. Am J Respir Crit Care Med 163: 413-419, 2001.

39. Scichilone N, Togias A. The role of lung inflation in airway hyperresponsiveness and in asthma. Curr Allergy Asthma Rep 4: 166-174, 2004.

40. Shaaban R, Leynaert B, Soussan D, Anto JM, Chinn S, de Marco R, Garcia-Aymerich J, Heinrich J, Janson C, Jarvis D, Sunyer J, Svanes C, Wjst M, Burney PG, Neukirch F, Zureik M. Physical activity and bronchial hyperresponsiveness: European Community Respiratory Health Survey II. Thorax 62: 403-410, 2007.

41. Shore SA, Fredberg JJ. Obesity, smooth muscle, and airway hyperresponsiveness. J Allergy Clin Immunol 115: 925-927, 2005.
42. Skloot G, Permutt S, Togias A. Airway hyperresponsiveness in asthma: a problem of limited smooth muscle relaxation with inspiration. J Clin Invest 96: 2393-2403, 1995.

44. Steinacker JM, Both M, Whipp BJ. Pulmonary mechanics and entrainment of respiration and stroke rate during rowing. Int J Sports Med 14: S15-S19, 1993.

45. Sue-Chu M, Larsson L, Moen T, Rennard SI, Bjermer L. Bronchoscopy and bronchoalveolar lavage findings in cross-country skiers with and without "ski asthma". Eur Respir J 13: 626-632, 1999.

46. Suman OE, Beck KC. Role of airway endogenous nitric oxide on lung function during and after exercise in mild asthma. J Appl Physiol 93: 1932-1938, 2002.

47. Wang L, Pare PD, Seow CY. Effects of length oscillation on the subsequent force development in swine tracheal smooth muscle. $J$ Appl Physiol 88: 2246-22450, 2000.

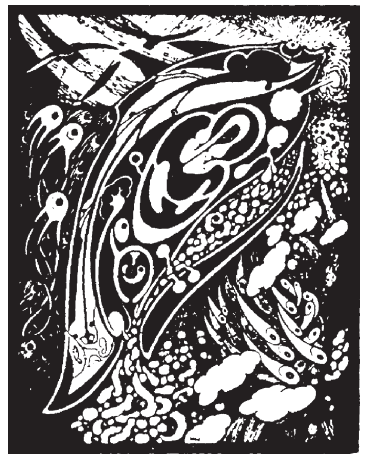

